\title{
A multi-modal network approach to model public transport accessibility impacts of bicycle-train integration policies
}

\author{
Karst T. Geurs ${ }^{1} \cdot$ Lissy La Paix ${ }^{1} \cdot$ Sander Van Weperen ${ }^{1}$ \\ Received: 14 January 2016 / Accepted: 14 September 2016 / Published online: 24 September 2016 \\ (C) The Author(s) 2016. This article is published with open access at SpringerLink.com
}

\begin{abstract}
Introduction In the Netherlands, the bicycle plays an important in station access and, to a lesser extent, in station egress. There is however fairly little knowledge in the potential effects of bicycle-train integration policies. The aim of this paper is to examine the impacts of bicycle-train integration policies on train ridership and job accessibility for public transport users. Methods We extended the Dutch National Transport Model (NVM) by implementing a detailed bicycle network linked to the public transport network, access/egress mode combinations and station specific access and egress penalties by mode and station type derived from a stated choice survey. Furthermore, the effects of several bicycletrain integration policy scenarios were examined for a case study for Randstad South, in the Netherlands, comprising a dense train network with 54 train stations.

Conclusions Our analysis shows that improving the quality of bicycle routes and parking can substantially increase train ridership and potential job accessibility for train users. Large and medium stations are more sensitive to improvements in
\end{abstract}

This article is part of Topical Collection on Accessibility and Policy Making

Karst T. Geurs

k.t.geurs@utwente.nl

Lissy La Paix

1.c.lapaixpuello@utwente.nl

Sander Van Weperen

sandervanweperen@gmail.com

1 Centre for Transport Studies, Faculty of Engineering Technology, University of Twente, P.O. Box 217, 7500AE,

Enschede, The Netherlands bicycle-train integration policies, while small stations are more sensitive to improvements in the train level of service.

Keywords Public transport accessibility $\cdot$ Bicycle-train integration $\cdot$ Bicycle parking $\cdot$ Stated choice experiment

\section{Introduction}

Improving the integration of bicycling with public transport encourages both bicycling and public transport use $[1,2]$ and is mutually beneficial. Bicycling supports public transport by extending the catchment area of public transport stops far beyond walking range and at much lower cost than local public transport and park-and-ride facilities for cars. Public transport services also can provide convenient alternatives when cyclists encounter for example bad weather [2]. Several studies in the literature have examined the impacts of bicycle-train integration policies on bicycle and public transport use [3,4] or passenger satisfaction with train use [5].

Although in the literature, modelling public transport accessibility is receiving increasing attention [6-8], few studies have examined non-motorised accessibility to public transport stops [9], or more specifically on potential accessibility impacts of bike-and-ride facilities and policies [10]. Recent studies however do demonstrate that transit ridership depends on the ability of the system to produce accessibility. For example, a logistic regression model for Hamilton, Canada, shows that a $4 \%$ increase in job accessibility would increase transit by $0.2-0.5 \%$ [11]. In the Netherlands, especially the bicycle plays a large role with a share of $38 \%$ as an access mode and $10 \%$ as an egress mode [5] and thus codetermines accessibility by public transport.

A comprehensive approach to measuring public transport accessibility however introduces a number of complexities. Firstly, not only accessibility to locations via public transport 
but also access to public transport by different modes has to be dealt with. This ideally implies a multimodal modelling approach including all possible transport modes, inclusion of public transport schedules, demand and supply interactions and adequate networks. For example, if Park-and-Ride is available, car choice should be included as access mode. In the transport modelling literature, the integration of road and public transport networks in an integrated multi-modal network ('super-network') model is receiving increasing attention [e.g., see 12-14]. Secondly, travellers perceive different parts of a public transport journey stages differently, such as the time spent in feeder modes, waiting and transfer times at public transport stops and in-vehicle travel time $[15,16]$. Travel time savings are also perceived differently between bicycle and local public transport feeder modes [17]. Therefore, specific penalties need to be assigned in the estimation of transport impedances to each access/egress mode in a multimodal trip. Those penalties can represent perceived impedance factors such as smoothness and convenience of the access/egress combinations. Moreover, the perceived quality of stations might also have an impact on those penalties, passengers would be more prone to wait $[18,19]$ or travel further to access more attractive stations [20].

Addressing the abovementioned complexity requires a level of integration between the transport modelling and accessibility modelling research fields beyond the current state of the practice. Most recent public transport accessibility studies are GIS-based estimation for example a combined transit and walking accessibility index [8], a potential job accessibility by high-speed train, based on the patronage from each zone, in-vehicle time, number of interchanges and interchange time, travel costs and parking costs [21] or mapping accessibility by time of the day and destination of trip [7]. However, these accessibility studies do not use transport demand models and lack attention for bicycle-train integration and transport impedances including transfer and other penalties.

The aim of this paper is to examine the impacts of bicycletrain integration policies on train ridership and job accessibility for public transport users. To do so, we integrate multimodal transport network modelling and accessibility modelling. Firstly, we extended an already operational Dutch national multi-modal transport network model to estimate the effects of detailed bicycle-train integration policy measures on train ridership and potential job accessibility by public transport in Randstad South, the wider metropolitan area of Rotterdam the Hague in the Netherlands. A detailed transport network was implemented, in which access and egress modes (bicycle, bus/tram/metro and walking) are connected to the main modes (public transport and car). Moreover, mode and station type specific value of time estimates were added in the travel impedance function, based on stated choice experiments, to represent the attractiveness of boarding and alighting stops. Bicycle-train integration policy scenarios are developed that reduce access/egress waiting time penalties and thus affect travel demand (destination and mode choice, route choice of public transport users). Secondly, a potential job accessibility measure is estimated based on the outputs of the multi-modal transport model, and a number of bicycle-train integration scenarios are developed and estimated. To the authors' knowledge, this is the first paper to examine the public transport accessibility impacts of bicycle-train integration policies.

The remainder of this paper is as follows: Section 2 describes the modelling approach and Section 3 the case study area. Section 4 describes the bicycle-train integration policy scenarios examined in the paper and Section 5 describes the model results. Section 6 presents the conclusions of the paper.

\section{Modelling approach}

\subsection{Multi-modal transport network model}

In this paper we extended the Dutch National Transport Model (NVM) [22] implemented in the OmniTRANS transport modelling suite to model the mobility and accessibility effects of changes in the (transport) infrastructure. The NVM-model is an aggregate four step transport demand model with simultaneous distribution/mode choice modelling [23] with detailed national multi-modal transport networks. In trip generation phase, the number of household, inhabitants, number and type of jobs, car ownership, workforce, age of inhabitants and educational places in each zone are the inputs for the calculation of the production from and attraction to each zone. In the trip distribution and mode choice modelling phase, the NVM uses two submodels: a destination/mode choice model and a public transport model. The destination/mode choice model uses three main modes: car, public transport (PT) and bicycle. The public transport model subsequently comprises train, bus, tram, metro and ferry networks. Park and ride facilities are associated with the car network. Each transport service is associated with the infrastructure (train with rail infrastructure, bus with road infrastructure, etc.). For each service the frequency, the stops and the travel time is implemented.

In the simultaneous destination/model choice model the different transport modes are compared with the generalised costs. The generalised costs for zone $i$ to zone $\mathrm{j}$ are calculated by:

$G C_{i j, m}=\beta_{i j, m}^{d} * d_{i j}+\beta_{i j, m}^{c} * t_{i j, m}$

Where $d_{i j}$ is the trip distance $(\mathrm{km}), \beta_{i j m}^{d}$ the travel cost parameter by mode $m$ (euro/km), $t_{i j}$ the travel time (hours) and $\beta_{i j m}^{c}$ the value of time (VoT) by mode $m$. The travel cost parameter varies by mode (car, bicycle, train, bus/tram/metro) and trip purpose (work, business, shopping, education or other), and are taken from national guidelines. Car travel cost parameters are based 
on fuel costs $(0.1145$ euro $/ \mathrm{km})$ and passenger occupancy rates, which differ between morning/evening/off peak periods. The VoT values are taken from Dutch appraisal guidelines and vary by mode (car, bike, public transport) and trip purpose. The VoT values range from 5.3 euro/h for a shopping trip by public transport to 30.5 euro/h for a business trip by car. ${ }^{1}$ The simulation results in an OD-trip matrix for each mode separately. The matrix for PT can be applied to the PT model, to assign these trips to the PT-network. Passengers travel from the zone to a stop with an access mode, from the stop to their destination with an egress mode. The waiting time for access at the stop is based on the frequency of the public transport service. The formula for the waiting time is:

$w_{l s}^{k}=0.3 * \frac{60}{F_{l s}}$

Where $w_{l_{S}}^{k}$ is the waiting time at access stop $\mathrm{s}$ by the access mode $k, F_{l s}$ is the frequency of the train line 1 at station $\mathrm{s}$. The value 0.3 is a penalty to put additional cost on a transit line which is not attributed to travel time or waiting time. The value is calibrated in the NVM model using a linear regression depending on the frequency of train line. The waiting time depends on the transit line and the stop where the transit line is boarded. In many applications the headway is divided by two to calculate the waiting time, but for the first boarding a waiting time of $0.5 \mathrm{x}$ headway is too long for low frequency lines as the passenger typically anticipates for this when leaving home. For any consecutive waits this is no longer true. The same formula is thus used for calculating the waiting time for transfers between public transport services, but the value 0.5 is used [25].

In the standard NVM-model walking and biking are combined as one access/egress mode with different speeds depending on trip distance. In our study, we extended the NVM model with the following access/egress modes: walktransit-walk, walk-transit-bicycle, bicycle-transit-walk, bicycle-transit-bicycle and car-transit-walk. With the new settings the public transport model calculates for these five combinations the generalised costs for travelling from each zone to each zone (using Eq. 1). A logit choice model is added to calculate the fractions for each access/egress combination for a zone to zone trip and a trip matrix for every access-egress combination is calculated. The model is specified as follows:

$P_{i}=\frac{\exp ^{-G C P T_{i}}}{\sum \exp ^{-G C P T_{j}}}$

\footnotetext{
${ }^{1}$ The VoT values by mode used in the NVM-model originate from a Stated Preference study by Hague Consulting Group in 1998. A new national VoT study was published in 2014, with lower VoT values for car driver $(-15 \%$, all purposes) and a higher VoT for train users $(+22 \%$, all purposes). The differences are mainly due to more advanced modelling techniques. See [24] for a description of the new and old national VoT values.
}

Where $\mathrm{i}$ represents the chosen alternative and $\mathrm{j}$ represents the choice set, by purpose $\mathrm{m}$. The parameters $\alpha_{i j}, \beta_{i j, m}, \gamma_{i j}$, ${ }_{m}$ and $\delta_{i j, m}$ are estimated for distance, travel time, waiting time and penalties, respectively. $d_{i j}, t_{i j}, W_{i j}$ and $p_{i j}$ represent the distance, travel time, waiting time and penalties. Parameters are estimated for each trip between origin $\mathrm{i}$ and destination $\mathrm{j}$, by mode $m$. In the Generalized Cost function (GC), distance, travel time, waiting time and penalties are added. Table 1 shows the parameter values of the cost function.

$$
G C P T_{i j, m}=\alpha_{i j m} * d_{i j}+\beta_{i j, m} * t_{i j, m}+\gamma_{i j, m} * W_{i j}+\delta_{i j, m} * p_{i j}
$$

The following procedure is followed to calculate fractions of access/egress mode shares. Firstly, the distances and travel times are calculated (Step 1). Distance and travel times depend on origin and (stop) destination. This function is applied for pairs of modes in access and egress combinations (Step 2) to calculate generalized costs. Choice modelling occurs based on generalized costs (Step 3). The results are input for travel time and distance matrix. The same procedure is repeated for different trip purposes (work, leisure, education, etc.).

For the implementation of these access and egress options, a detailed bicycle network obtained from the Dutch Cyclist's Union [26] was implemented. The network includes all bicycle trails (on- and off-street trails) in the study area for the year 2013, including link characteristics (i.e. road quality, lighting and nuisance). Here it is assumed that cycle speed is $15 \mathrm{~km} / \mathrm{h}$ to and from the transit stops and pedestrians use the same infrastructure walking $5 \mathrm{~km} / \mathrm{h}$ on this network. Furthermore, the influence areas of PT stops is set to $3 \mathrm{~km}$ and $5 \mathrm{~km}$ for walking and cycling, respectively. In addition, the basic car network is added to the transit network for the Netherlands. This network is connected with the centroids of all zones in the Netherlands and the railway stations in study area. This makes it possible to model park and ride.

\subsection{Operationalising accessibility}

Accessibility can be defined and operationalised in many different ways. Many different accessibility definitions and operationalisations in accessibility models and instruments have in the past decades been developed and applied by researchers from several academic fields (e.g., urban geography, rural geography, health geography, time geography, spatial economics, transport engineering). An overview of the many different definitions and operationalisations is beyond the scope of this paper. There are extensive reviews on accessibility measures [27-29] in general and public transport accessibility in particular [e.g., 22]. Accessibility measures can be categorised in several ways. Geurs and Van Wee [29] distinguish between four groups of accessibility measures. Firstly, infrastructure-based measures analyse the performance or 
Table 1 Parameter values in the generalised cost function of the access/egress mode choice model

\begin{tabular}{lllll}
\hline Mode & $\boldsymbol{\alpha}$ (Distance) & $\mathrm{B}$ (Travel Time) & $\gamma$ (Waiting Time) & $\boldsymbol{\delta}$ (Penalties) \\
\hline Access/egress by car & 0.1 & 18 & 6.86 & 6.86 \\
Access/egress by bicycle & 0.05 & 16 & 6.86 & 6.86 \\
Access/egress by walk & 0.05 & 6.86 & 6.86 & 6.86 \\
Public transport & 0.1 & 6.86 & 6.86 & 6.86 \\
\hline
\end{tabular}

service level of transport infrastructure. These measures vary from simple travel time or congestion level measures to more complex network connectivity/centrality measures based on graph theory. Secondly, location-accessibility measures are a wide range of measures analysing access to spatially distributed activities, with threshold-based measures [e.g., 30] and Hansen's gravity-based accessibility measure [31] as most popular ones. Thirdly, person-based accessibility measures used to analyse accessibility at individual level, taking individual limitations regarding freedom of action in the environment, into account. Fourthly, utility-based accessibility measures, such as logsum accessibility, analysing the welfare benefits that people derive from levels of access to the spatially distributed activities [e.g., 32, 33]. Recently, a new type of 'perceived' accessibility measures was proposed, defining accessibility as the expected number of opportunities "available" for a subject to perform an activity, which contrasts with location-based and utility-based measures which assume that all opportunities are potentially available [34].

The complexity of the concept of accessibility and of its perception by travellers implies that ideally multiple indexes are to be used in accessibility studies, to provide a better depiction of how individuals respond to the spatial structure of travel opportunities, and configurations and modalities of the transportation networks $[35,36]$. In this paper, however, we are interested in the spatial and network effects of bicycle-train integration policy scenarios at the regional level and not in comparing outcomes of different accessibility specifications. Furthermore, the choice and level of detail of accessibility indicators in this paper is constrained as the indicators are to be estimated using outputs of the NVM-model, which provide a high spatial resolution but does not allow estimations of accessibility for different population segments. A Hansenbased potential accessibility measure is applied here as a simple and effective measure to examine the spatial and network effects of transport infrastructure scenarios. This measure overcomes the well-known problems with the arbitrary selection of time thresholds and extreme sensitiveness of small travel time changes associated with threshold-based accessibility measures [29]. Person-based accessibility measures are, because of their data need, unfortunately beyond the scope of this research. Logsum accessibility can easily be used to derive accessibility benefits by population segment, but estimating spatial and mode-specific accessibility effects is not straightforward as zones/postcodes and modes are endogenous choice variables in mode/destination logit models [33]. A potential accessibility measure is used here, measuring the number of opportunities of some type of activity which can be reached over transport networks, weighting opportunities by an impedance function as follows:

$A_{i}^{s_{k}}=\sum_{i=1} D_{j} * f\left(t_{i j}\right)$

Where $A_{i}^{S_{k}}$ is the accessibility in transport zone $i$ for scenario $\mathrm{S}_{\mathrm{k}}, D_{j}$ is the number of destination opportunities (jobs) in a number of zones $j$ reachable from zone $i$ in (a maximum of) 180 min. $t_{i j}$ is the travel time by public transport between $i$ and $j$ (modelled with the NVM-model). $\mathrm{f}(\mathrm{t})$ is the distance decay function of travel time. A maximum of $180 \mathrm{~min}$ is used to exclude the influence of destinations far away from the study area on the accessibility index. The effect of this threshold on the accessibility index is small, however. According to the data from the 2014 Dutch National Travel Survey, less than $2.5 \%$ of public transport trips and less than $0.5 \%$ of car trips made by residents in Randstad South are longer than $180 \mathrm{~min}$.

In this paper we focus on accessibility to jobs, however, job locations are a suitable proxy for many types of activity [37, 38] since most types of activity participation are associated with the location of some type of corresponding employment (i.e. medical jobs for health care, retail jobs for shopping, etc.)

In the accessibility literature, exponential and power specifications of the distance decay function are often used but also other specifications such as inverse-potential, log-normal, loglogistic, exponential square-root and half-life functions are used [e.g., see for discussions 39-41]. From comparative studies is clear that the choice of the distance decay function impacts the outcomes of gravity-based accessibility measures, but generated spatial patterns can be very similar [35]. We applied and estimated the model fit of the inverse-potential, negative-exponential, gaussian and log-logistic distances decay functions using data from the 2014 Dutch National Travel Survey [42]. The log-logistic formulation was found to have the best fit with the observed data, using the Akaike information criterion (AIC) indicator to compare models. Other studies also find log-logistic decay functions to provide good model fits to model job accessibility [e.g., 43, 44], reflecting that for commuters, sensitivity to travel cost (or time or distance) is stronger for intermediate distances than for short and long distances. Thorsen et al. [44] also provide a theoretical justification for such an S-shaped curve, based on the idea that 
short distances give random commuting flows, whereas long distances are governed by a minimum cost principle. The loglogistic formulation is as follows:

$f\left(t_{i j}\right)=\frac{1}{1+\exp \left(a+b \ln t_{i j}\right)}$

Where $t_{i j}$ is the travel time between $i$ and $j$, and a and $\mathrm{b}$ are parameters to be estimated. The parameters for log-logistic distance decay function were estimated for commuting trips of residents of the Randstad South, and shown in Table 2. Table 2 also shows the t-test below for each parameter. All values are statistically significant different from zero, under the $95 \%$ confidence level. T-test is larger than 1.96.

The distance decay functions for the study area are steeper than the national average, with $\mathrm{a}$ and $\mathrm{b}$ parameters -11.156 and 2.838, respectively. Randstad South is one of the most densely populated areas in the Netherlands and residents make on average shorter trips. For example, in Randstad South, $62 \%$ of public transport trips is shorter than $45 \mathrm{~min}$ (including access/egress) compared to $38 \%$ for the Netherlands.

The improvement in accessibility in zone $i\left(A_{i}^{\Delta}\right)$ is represented as follows:

$A_{i}^{\Delta}=\frac{A_{i}^{s_{k}}-A_{i}^{s_{\mathrm{o}}}}{A_{i}^{s_{\mathrm{o}}}} \cdot 100$

Where $A_{i}^{S_{k}}$ is the accessibility measure in zone $i$ during the scenario $S_{k}$, estimated with the NVM-model, where $k$ is the scenario number, and $A_{i}^{s_{0}}$ is the accessibility measure in reference scenario (2012).

\section{Case study and station types}

The case study of this paper is the wider Rotterdam-The Hague metropolitan area in the Netherlands which comprises 3 million residents and is one the most urbanised areas in the Netherlands. This area is also known as Randstad South in Dutch policy and planning documents and includes several medium-sized cities such as Leiden, Gouda and Dordrecht. The area has a dense railway network and comprises 54 train stations. In this study, we use the standard station typology from the Netherlands Railways (NS), based on the size and function of train stations [45]. The six NS station types are defined as follows:

Table 2 Parameter values, standard error and t-test of log-logistic distance decay function

\begin{tabular}{llll}
\hline Parameter & Estimate & Std. error & t-test \\
\hline A - PT & -11.467 & 0.086 & -133.337 \\
B - PT & -3.007 & 0.022 & -136.682 \\
\hline
\end{tabular}

- NS-type 1: very large stations in city centres and 50.000 passengers per day or more. In the study area, Rotterdam CS and The Hague CS fall in this category.

- NS-type 2: large stations in medium-sized cities with 50,000 passengers per day or less, including for example Delft, Dordrecht, Gouda and Leiden CS;

- NS-type 3: suburban commuter stations with 16.000 passengers per day or less, including Rotterdam Alexander, Rotterdam Blaak and Schiedam Centrum and other stations;

- NS-type 4:medium-size stations in the centre of small town or village with 10.000 passengers per day or less, including Rijswijk, Zoetermeer and Waddinxveen and other stations;

- NS-type 5: suburban stations without a clear commuter function with 5.000 passengers per day or less, including Delft Zuid, Gouda Goverwelle, The Hague Mariahoeve and other stations;

- NS-type 6: stations in rural small towns or villages with less than 5.000 passengers per day, including Barendrecht, Voorschoten and other stations.

Figure 1 shows the study area and the locations of the train stations by station type.

\subsection{Survey and stated choice experiment for access and egress modes to train stations}

A combined revealed/stated preference survey was conducted in the period June-July 2013 among 1524 respondents living in the catchment area of train stations in Randstad South. Here, we only briefly describe the design of the survey; we refer to La Paix and Geurs [17, 46] for more extensive descriptions.

The survey comprised revealed preference questions and stated choice experiments. The revealed preference questions included a user assessment of the perceived quality of different aspects of departure and arrival stations. A total of 23 aspects were scored by the respondents using a 10-point Likert scale, covering the 9 aspects of stations facilities (including the quality of car parking, number of train connections, social safety, liveliness of stations), 9 aspects of cyclist facilities (including quality of bicycle parking, directness of bicycle routes, social safety and comfort of routes) and 5 factors of pedestrian facilities (including quality of walking route, protection against bad weather conditions, traffic and social safety). The criteria to analyse in the assessment were identified via factor listing and literature review. Figure 2 shows the average score (10 point scale) for cycling facilities by station type. The scores range from 5.3 (quality of bicycle rental at arrival station for station types 4 and 5) to 7.5 (comfort and safety of bicycle lanes for station type 6). The smallest train stations (NS-type 5 and 6) have higher scores for most of the 


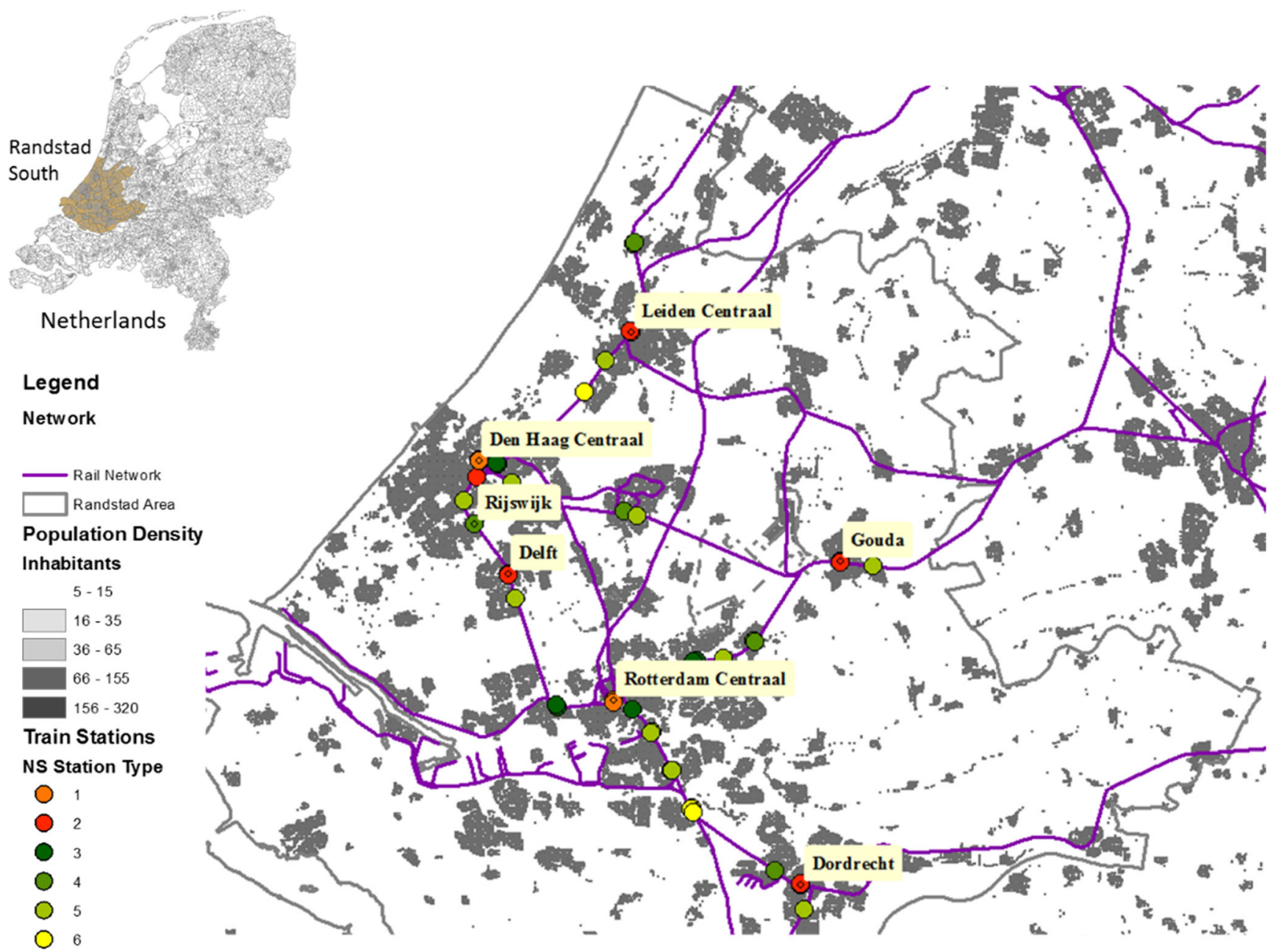

Fig. 1 Randstad South, railway network and locations of railway stations

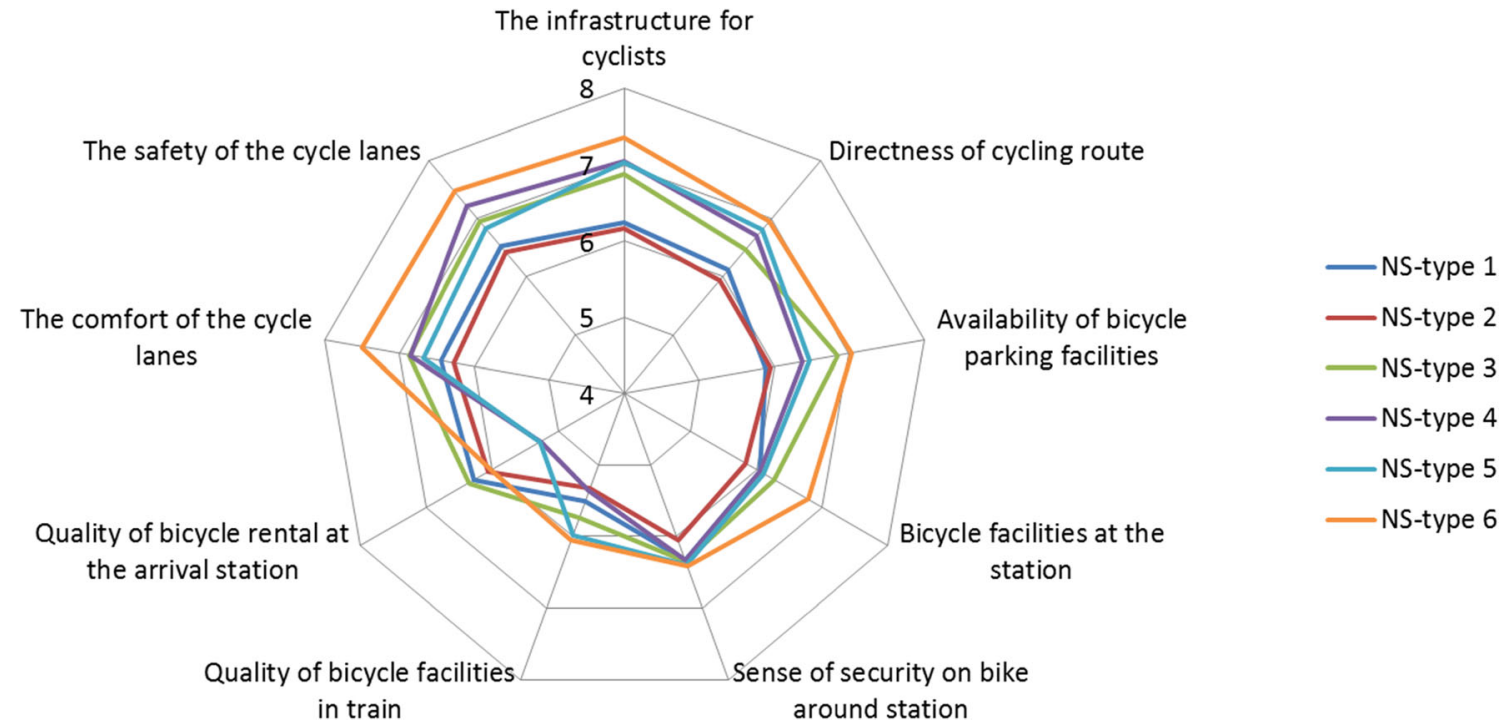

Fig. 2 Average scores of cycling facilities by station type in Randstad South 
factors than large stations (NS-type 1 and 2), in particular for safety and comfort of bicycle routes. Large stations in medium-sized cities (NS-type 2) have the lowest average score for bicycle facilities (6.0), whereas rural stations (NS type 6) have the highest average score (6.8). The large stations have relatively low scores for the availability of bicycle parking facilities, cyclist infrastructure and directness of bicycle routes to the station (average score of 6). These results were used as input for the design of the different scenarios examined with the NVM-model.

The second part of the survey, the stated choice experiments, was composed by 12 choice situations, 6 of which were for access and 6 for egress mode choice. In earlier work [17], the choice experiments were used to estimate mixed logit models of access/egress mode choice including travel time, costs and quality. In this paper, the value of time (VoT) for access/egress modes were obtained from these choice models, and used as inputs for the scenarios in the National Transport Model (explained in more detail in Section 4). Table 3 shows the VoT values for access/egress modes for Rotterdam CS, The Hague CS (both NS type 1) and the combined stations of NS station type 2, station type 3-4 and station type 5-6. Table 3 firstly shows that the VoTs for access/egress range between 16.5 to $27.4 \mathrm{euro} / \mathrm{h}$, which is significantly higher than the VoT for in-train time. A recent stated choice study in the Netherlands found a VoT for train users of $9 \mathrm{euro} / \mathrm{h}$, for train commuters 11.5 and train business travellers 19.75 euro/h [24]. In the literature, it is well-known that the valuations of in-vehicle and out-vehicle time substantially differ, and several studies have examined VoT of access to train stations. Metastudies on British public transport VoT studies have found average VoT of access modes between 1.8 times the in- vehicle time $[47,48]$, implying that travellers find in-vehicle times less burdensome than access travel time. Secondly, the VoTs differ between station type, which reflects a different mix of users and the relationship between access mode choice and station departure choice. Almost half of the Dutch railway travellers choose a departure station which is not the nearest station to their places of residence [49]. The choice of the departure station depends on the quality of the station (e.g., frequency of trains, station facilities) and the accessibility of the station by different modes. For example, large train stations can be better accessed by bus/tram/metro, as frequencies are higher. Also, train passengers often do not walk to the nearest local train station but cycle a longer distance to a larger railway station with a higher frequency of trains or with more direct connections.

\section{Developing scenarios in the national transport model}

To examine the effects of bicycle-train integration policies on train ridership and job accessibility, six scenarios were developed and implemented in the NVM-model. The first 5 scenarios deal with a range of possible bicycle-train integration policies, based on user assessment of the quality of bicycle facilities and the time or cost attribute levels of the stated choice experiments. The last scenario examines the impacts of an increase in the frequency of local trains for the Leiden Dordrecht corridor as a benchmark for the impacts of the bicycle-integration policy scenarios. Table 3 summarises the operationalisation of the six scenarios. The scenarios are implemented over different station numbers, depending on the

Table 3 Willingness to Pay (WtP, in Euro), Equivalent Time Saving (ETS, in minutes) and Waiting Time Reduction (WTR, minutes) by scenario

\begin{tabular}{|c|c|c|c|c|c|c|c|c|c|c|}
\hline Scenario & $\begin{array}{l}\text { Station type } \\
\text { VOT } € / \mathrm{hr}\end{array}$ & $\begin{array}{l}\text { Rotterdam CS } \\
€ 27.4\end{array}$ & $\begin{array}{l}\text { The Hague CS } \\
€ 17.6\end{array}$ & $\begin{array}{l}\text { NS-type } 2 \\
€ 17.7\end{array}$ & $\begin{array}{l}\text { NS- type } 3 \\
€ 16.5\end{array}$ & $\begin{array}{l}\text { NS- type } 4 \\
€ 16.5\end{array}$ & $\begin{array}{l}\text { NS- type } 5 \\
€ 22.8\end{array}$ & $\begin{array}{l}\text { NS- type } 6 \\
€ 22.8\end{array}$ & Avg. WTR & $\begin{array}{l}\text { \# stations } \\
\text { affected }\end{array}$ \\
\hline 1 & \multicolumn{8}{|c|}{ Perceived quality of station access (variable percentage) } & -1.1 & 35 \\
\hline \multirow[t]{2}{*}{2} & \multicolumn{8}{|c|}{ Free bicycle parking } & -3.9 & 38 \\
\hline & ETS (min) & 2.7 & 4.3 & 4.2 & 4.6 & 4.6 & 3.3 & 3.3 & & \\
\hline \multirow[t]{3}{*}{3} & \multicolumn{8}{|c|}{ Proximity to platform } & -5.2 & 38 \\
\hline & WTP (euro) & -1.5 & -1.5 & -1.5 & -1.6 & -1.6 & -2.0 & -2.0 & & \\
\hline & ETS (min) & 3.3 & 5.1 & 5.1 & 5.9 & 5.9 & 5.2 & 5.2 & & \\
\hline \multirow[t]{3}{*}{4} & \multicolumn{8}{|c|}{ No delays on cycle routes } & -2.6 & 38 \\
\hline & WTP (euro) & -0.7 & -0.7 & -0.7 & -1.0 & -1.0 & -0.9 & -0.9 & & \\
\hline & ETS (min) & 1.4 & 2.2 & 2.2 & 3.5 & 3.5 & 2.3 & 2.3 & & \\
\hline \multirow[t]{3}{*}{5} & \multicolumn{8}{|c|}{ Cycle time to station } & -6.0 & 38 \\
\hline & WTP (euro) & -1.5 & -1.5 & -1.5 & -1.9 & -1.9 & -2.6 & -2.6 & & \\
\hline & ETS (min) & 3.2 & 5.0 & 5.0 & 6.9 & 6.9 & 6.7 & 6.7 & & \\
\hline 6 & \multicolumn{9}{|c|}{ Increased Sprinter frequencies } & 19 \\
\hline
\end{tabular}

Source of WTP and ETS estimates: [17] 
scenario design. The scenarios change the impedance of access/egress and/or public transport modes and thus affect destination and mode choice (between car, public transport modes and bicycle in the simultaneous destination/mode choice mode) and chosen routes of PT-users for different public transport modes (bus, tram, metro, train) (in the NVM public transport model). The following paragraphs describe the scenario in more detail.

\section{Scenario 1: Perceived quality of station access}

The aim of this scenario is to examine the influence of improvements in perceived connectivity and station facilities on access time. An ordered logit model was estimated using the results from the survey. The scores of perceived connectivity and station facilities of departure and arrival stations are independent variables and the stated access time by bicycle (in five categories 2-5, 5-10, 10-15, 15-20, > $20 \mathrm{~min}$.) is the dependent variable. We selected variables with a negative sign (access time decreases when the rating increases) and which are significant $(p<0.10)$. The factor quality of parking facilities was used a proxy for the quality of station facilities and the factor comfort of cycle lanes to the train station as a proxy for connectivity. The elasticity of changes in access time and changes in connectivity and facilities variables was translated into access time reductions at the train stations. For each station, an average score was calculated, and the amount of improvement is determined by assuming the average rating could increase to the highest value that is currently present in the network (i.e. Rotterdam CS with an average score of 8 out of 10). Subsequently, the corresponding reduction in waiting time was calculated based on the elasticity. Therefore, for each railway station in the network a specific percentage of reduction in waiting time was applied. This decrease in access time was implemented in the waiting time formula in the NVM model. This results in the following formula:

$w_{l s}^{k}=\left(1-\Delta t_{s}\right) * 0.3 * \frac{60}{F_{l s}}$

Where $w_{l s}^{k}$ is the waiting time at access stop s by the access mode $k$, in this case bicycle; $\Delta t$ is the percentage of access time to be reduced, which means that the original waiting time is affected by a percentage; $F_{l s}$ is the frequency of the train line 1 at station s. Table 6 in the Appendix shows the exact increment by station. The measure is implemented in 35 stations in the study area. The average reduction of waiting time is $34 \%$ and the average waiting time reduction for the 35 stations is $1.1 \mathrm{~min}$.

\section{Scenario 2: Free bicycle parking}

Until recently, there were two bicycle parking options at train stations in the Netherlands: (1) free and unguarded parking or (2) guarded/automated facilities for $1.25 € /$ day
(2013 price) (NS 2015). In 2014, however, NS opened guarded bicycle parking facilities at some major and middle-sized railway stations which can be used for free for $24 \mathrm{~h}$ and some other railway stations started offering free guarded/automated facilities which can be used up to a certain period (e.g. 14 days). At the time of writing (July 2016), there are free guarded bicycle parking facilities in the study area at Leiden CS and Delft CS. In this scenario, we assume all stations offer free guarded bicycle parking, which is a substantial improvement over the current situation. The effects of this policy are examined with this scenario for access by bicycle to stations. Then, based on the VoT by bicycle, the reduction in (equivalent) travel time for cycling is calculated. The VoTs by stations type are retrieved from the survey. The travel time can be used in the NVM-model to reduce the bicycle time and consequently improving its attractiveness.

For the implementation of this scenario in the NVMmodel the average waiting time is calculated for each station. This average waiting time is calculated with use of the number of cyclists who access a specific train station and choose a transit line with a specific frequency. The reduction in waiting time by station type, as described above, is subtracted of the average waiting time. Therefore, the waiting $w_{l s}^{k}$ time is implemented in the NVM-model as follows:

$w_{l s}^{k}=\left(0.3 * \frac{60}{F_{l s}}\right)-\Delta t$

$w_{l s}^{k}$ is the waiting time at access stop s by the access mode $k$, in this case bicycle; $\Delta t$ is the access time reduction, which in this case is a fixed number by station (mode-station constant); $F_{l s}$ is the frequency of the train line $l$ at station $s$. The measure is implemented in 38 stations in the study area, and the average waiting time reduction for bicycle-train trips in this scenario is $3.9 \mathrm{~min}$.

\section{Scenario 3: Proximity to platform}

One of the main problems identified at the stations was the quality of bicycle parking, which includes proximity, cost and bicycle parking capacity. This scenario represents the effects of an improvement of the availability of bicycle places within 2 min walking form the platform. Via this implementation, the scenario represents a proxy of bicycle parking capacity, e.g. larger capacity reduces the searching time for parking spot. The time saving in minutes for access by bicycle is calculated using the values of time and the willingness to pay, presented in Table 3. This scenario is implemented in the same way in the NVM model as described for scenario 2. The measure is implemented in 38 stations in the study area, and the average waiting travel time reduction for bicycle-train trips is $5.2 \mathrm{~min}$. 


\section{Scenario 4: No delays on cycle routes}

This scenario represents the situation where cyclist can be sure that there are no delays on the route to the station. This reduces the travel time, because they can leave later from their home place. The travel time savings are calculated with the willingness to pay as presented in Table 3. The travel time savings per station type are shown in Table 3 as well. This scenario is implemented as the aforementioned scenarios 2 and 3, via Eq. 9. The measure is implemented in 38 stations in the study area, and the average waiting travel time reduction in this scenario is $2.6 \mathrm{~min}$.

\section{Scenario 5: Cycle time to station}

Scenario 5 is a scenario assuming a reduction of the travel time for access by bicycle with $5 \mathrm{~min}$ due to less interruption on the route and priority at traffic lights and other intersections. This was one of the attribute levels in the stated choice experiment. An average reduction of 5 min cycling time is a substantial travel time reduction, given that cyclists typically travel 10-15 min or less (1.5 to $3.5 \mathrm{~km}$ distance) to the train station, and the average in-vehicle train travel time within the Randstad area is $30 \mathrm{~min}$. The WTP for reducing $5 \mathrm{~min}$ along the bicycle route is calculated from the stated choice experiment [17]. The WTP is converted to waiting time reductions at the train stations and implemented in the NVM-model, via the waiting times modifications as Eq. 9. The measure is implemented in 38 stations in the study area, and the average (equivalent) travel time reduction for bicycle -train trips is $6 \mathrm{~min}$.

\section{Scenario 6: Increased train frequencies}

Local and regional governments in Randstad South, the Netherlands Railways (NS) and the national railway manager Prorail work together in a regional Transit Oriented Development (TOD) programme called Stedenbaan [50]. A range of policy measures, including densification of housing and offices around train stations and bicycle-train integration policies, are implemented to achieve an increase in train ridership and thus ticket revenues to cover the operational cost of an increase in the train frequency of local ('sprinter') trains from four to six per hour per direction on the corridor Leiden The Hague CS - Rotterdam CS - Dordrecht by the year 2020. Here, we examine the impacts of the frequency increase for the 19 stations on the Leiden - Dordrecht corridor in the base year (2012) as a benchmark for the bicycle-integration policy scenarios.

\section{Train ridership and job accessibility impacts}

\subsection{Change in number of train passengers}

The NVM-model was used to estimate the potential changes in destination, mode choice and routes of PT-users for different public transport modes (bus, tram, metro, train) in the morning peak (7-9 AM), assuming a full implementation of the policy scenarios in the base year 2012, relative to the reference scenario. Table 4 shows the effects of the policy scenarios on the number of train passengers (2012 morning peak) by station type. The strongest overall increase in ridership results from the $5 \mathrm{~min}$ reduction in cycle time to the station (Scenario 5, $16 \%$ increase), followed increasing the availability of bicycle parking within $2 \mathrm{~min}$ from the platform (Scenario 3, $14 \%$ increase) and the introduction of free bicycle parking (Scenario 2, $11 \%$ increase). It means that one of the most important attributes of bicycle access to the station is the location of bicycle parking, and users are highly willing to pay for improvement of these facilities. It also means that travel time to the station is highly valued by public transport users. This result is in line with other studies on the walkingpricing trade-off at bicycle parking at train stations the Netherlands. Molin et al. [51] conducted a choice experiment on bicycle parking facilities at Delft CS and find that utility of bicycle parking facilities decrease rapidly (a quadratic relationship) with walking time to the platform. They suggest that

Table 4 Percent changes in the number of train users by station type and scenarios, 2012 morning peak

\begin{tabular}{|c|c|c|c|c|c|c|}
\hline Station Type & $\begin{array}{l}\text { Perceived quality } \\
\text { of station access ( } \mathrm{Sc} 1)\end{array}$ & $\begin{array}{l}\text { Free bicycle } \\
\text { parking (Sc2) }\end{array}$ & $\begin{array}{l}\text { Proximity to } \\
\text { platform (Sc3) }\end{array}$ & $\begin{array}{l}\text { No delays on } \\
\text { cycle routes ( } \mathrm{Sc} 4)\end{array}$ & $\begin{array}{l}\text { Cycle time } \\
\text { to station (Sc5) }\end{array}$ & $\begin{array}{l}\text { Increased Sprinter } \\
\text { frequencies (Sc6) }\end{array}$ \\
\hline NS-type 1 & $-1 \%$ & $6 \%$ & $13 \%$ & $5 \%$ & $8 \%$ & $1 \%$ \\
\hline NS-type 2 & $1 \%$ & $14 \%$ & $16 \%$ & $6 \%$ & $18 \%$ & $1 \%$ \\
\hline NS-type 3 & $2 \%$ & $11 \%$ & $20 \%$ & $9 \%$ & $18 \%$ & $15 \%$ \\
\hline NS-type 4 & $7 \%$ & $18 \%$ & $31 \%$ & $14 \%$ & $28 \%$ & $14 \%$ \\
\hline NS-type 5 & $7 \%$ & $12 \%$ & $17 \%$ & $1 \%$ & $23 \%$ & $21 \%$ \\
\hline NS-type 6 & $5 \%$ & $16 \%$ & $21 \%$ & $5 \%$ & $30 \%$ & $12 \%$ \\
\hline Total & $2 \%$ & $11 \%$ & $14 \%$ & $5 \%$ & $16 \%$ & $3 \%$ \\
\hline
\end{tabular}


Fig. 3 Effects of bicycle-train integration policy scenarios on the absolute number of train users in Randstad South by NS station type, 2012 morning peak

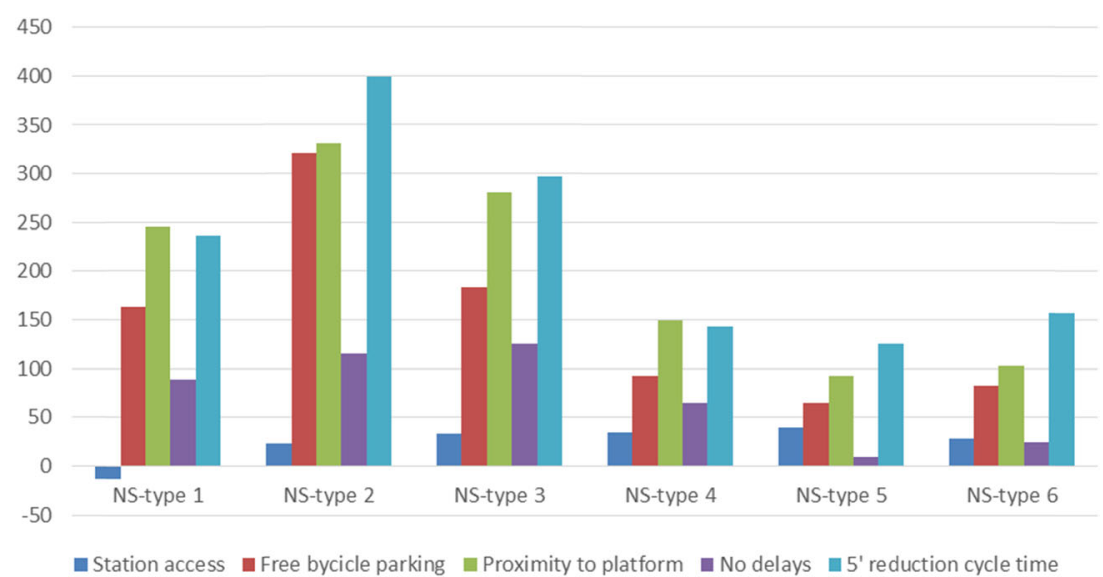

charging for all bicycle-parking facilities close to the platforms may be a feasible solution for distributing scarce bicycle places at Dutch railway stations.

Furthermore, the largest percent changes in ridership for the different policy scenarios are found at small and middlesized and small train stations with 10,000 passengers per day or less (type 4 to 6 ). Although our survey suggests that train users perceive the quality of routes and bicycle facilities at these stations as relatively good, the NVM-model shows that a reduction of cycling time and cost in station access has relative strong effects on ridership at these stations. In absolute terms, however, the bicycle-train integrations scenarios have stronger effects on train passengers using large and commuter train stations (NS-types 1-3). This is visualised in Fig. 3.

Table 4 and Fig. 3 show that Scenario 1 surprisingly slightly reduces the number of train passengers in Rotterdam CS and The Hague CS (stations type 1) due to distributional effects in the routes of PT-users; stations nearby (type 2/3) become more attractive and attract passengers from the central stations. Scenario 1 upgrades the assessment of quality infrastructure to 8 in all stations, making smaller stations more attractive, while the bigger stations remain with the same quality level. The increase in the frequency of local trains in the corridor Leiden-Dordrecht (Scenario 6) has the strongest percent effect on the number of train use at station type 5 , which currently have the lowest train level-of-service (Table 4). The intercity railway stations Hague CS and Rotterdam CS (NS type 1 stations) hardly benefit as increase of the frequency of local trains represents a marginal change in the already high level of service. Four of the five bicycle-train integration policy scenarios are more powerful in producing ridership increases than the scenario with increased sprinter frequencies. However, it should be noted that the bicycle-train policy measures affect more train stations; these are assumed to be implemented at 35-38 train stations in the case study area and the frequency increase affects 19 stations in the corridor.

\subsection{Changes in job accessibility by public transport}

Table 5 shows impacts for the 6 scenarios on job accessibility by public transport, using the potential job accessibility indicator (eq. 5). As can be seen, the largest effects, in magnitude, belong to scenario 5 and 3 , consistent with the train ridership effects. By contrast, scenarios 1 and 6 show slightly diluted results. Thus, bicycle-train integration policy measures seem to be more effective in increasing job accessibility than improvements in the frequency of local trains. Note again, however, that the increase of the frequency of local trains applies to only one corridor in the study area and thus affects less train stations (19 in total).

Table 5 Overall change in job accessibility by public transport, relative to 2012 network

\begin{tabular}{|c|c|c|c|c|c|c|}
\hline Station type & $\begin{array}{l}\text { Perceived station } \\
\text { access }(\mathrm{Sc} 1)\end{array}$ & $\begin{array}{l}\text { Free bicycle } \\
\text { parking }(\mathrm{Sc} 2)\end{array}$ & $\begin{array}{l}\text { Proximity to } \\
\text { platform }(\mathrm{Sc} 3)\end{array}$ & $\begin{array}{l}\text { No delays on } \\
\text { cycle routes ( } \mathrm{Sc} 4)\end{array}$ & $\begin{array}{l}\text { Cycle time to } \\
\text { station }(\mathrm{Sc} 5)\end{array}$ & $\begin{array}{l}\text { Increased train } \\
\text { frequency (Sc6) }\end{array}$ \\
\hline NS-type 1 & $0.8 \%$ & $7.7 \%$ & $9.6 \%$ & $3.9 \%$ & $9.8 \%$ & $0.4 \%$ \\
\hline NS-type 2 & $1.3 \%$ & $10.0 \%$ & $12.6 \%$ & $4.9 \%$ & $12.8 \%$ & $0.5 \%$ \\
\hline NS-type 3 & $0.8 \%$ & $8.4 \%$ & $11.2 \%$ & 5.6 & $12.9 \%$ & $0.6 \%$ \\
\hline NS-type 4 & $0.6 \%$ & $4.3 \%$ & $5.9 \%$ & $3.0 \%$ & $6.9 \%$ & $0.5 \%$ \\
\hline NS-type 5 & $1.1 \%$ & $4.8 \%$ & $6.9 \%$ & $2.9 \%$ & $8.1 \%$ & $0.8 \%$ \\
\hline NS-type 6 & $1.1 \%$ & $2.5 \%$ & $4.31 \%$ & $1.7 \%$ & $5.9 \%$ & $1.7 \%$ \\
\hline Total & $0.8 \%$ & $4.8 \%$ & $6.5 \%$ & $2.8 \%$ & $7.3 \%$ & $0.6 \%$ \\
\hline
\end{tabular}


The spatial distribution of changes in job accessibility of the scenarios is also very different. Figures 4, 5 and 6 show the effect of free guarded bicycle parking (scenario 2), having bicycle parking within 2 min from the train platform (scenario 3) and the increased sprinter frequencies (scenario 6). The figures show bicycle-train integration scenarios 2 and 3 produce relatively large localised effects around stations, in particular at NS-types 1 to 3 , in whereas the increase of the frequency of local trains (scenario 6) produces smaller effects, with the highest effects at NS-type 6 stations. The latter also produces regional effects, beyond the corridor. This illustrate that the bicycle-train integration and train level-of-service measures can strengthen each other and broaden the scope of job accessibility impacts.

Comparing Tables 4 and 5, we can observe that accessibility and ridership increase simultaneously, which is consistent with other studies [11]. The relation between accessibility and ridership is however not proportional, and it is also station specific. For example, large and medium-sized stations are more sensitive to changes in bicycle network, while small stations are more sensitive to changes in the train service levels.

Figure 7 visualises potential job accessibility change for the 6 scenarios (relative to the base year 2012), for 19 stations on Leiden-Dordrecht corridor. The accessibility reaches the high values in northern Randstad (i.e.
Leiden Centraal), while rapidly decreases in specific stations in the south (i.e. Barendrecht and Dordrecht Zuid). The largest increase in job positions takes place in small and medium-sized stations (e.g. Den Haag Laan van NOI and Delft Zuid).

Figure 7 also illustrates, as noted earlier, that the five bicycle-train integration policy scenarios are more powerful in producing job accessibility changes than the scenario with increased sprinter frequencies. Moreover, the five bicycle-train integration policy scenario follow a similar pattern along the corridor, which can be expected because of similarities in the implementation. Interestingly, the perceived access scenario (scenario 1) has similar sized effects as the train frequency increase (scenario 5). Scenario 1 also shows peaks in specific small stations (e.g. Delft Zuid and Den Haag Moerwijk) and large stations (e.g. Leiden and The Hague CS) are less affected, or less sensitive.

\section{Conclusions}

In the Netherlands, the bicycle plays an important role in station access and, to a lesser extent, in station egress. There is however fairly little knowledge in the potential effects of bicycle-train integration policies. The aim of this paper was to examine the impacts of bicycle-train

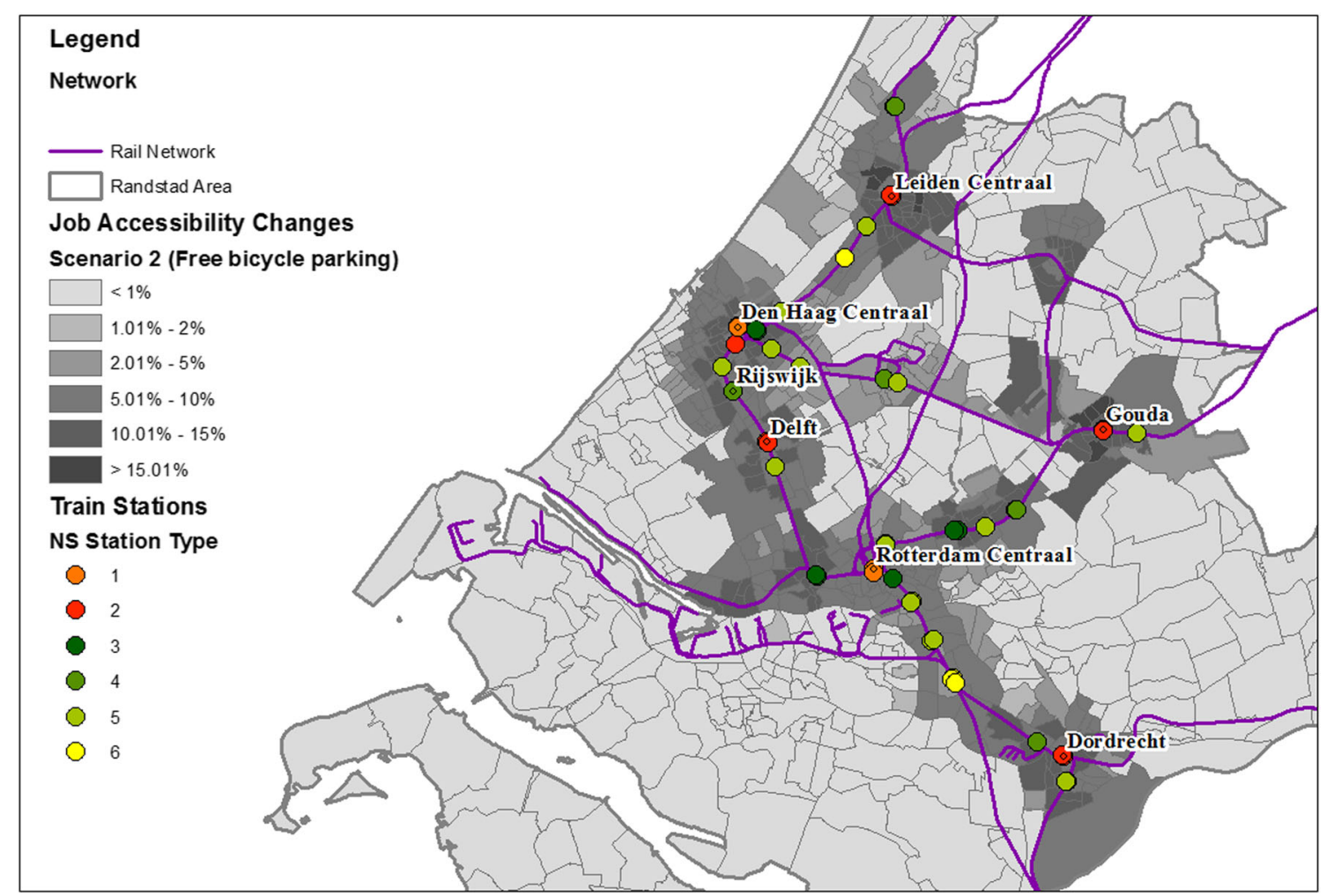

Fig. 4 Effect of free guarded bicycle parking (scenario 2) on potential job accessibility by public transport in Randstad South, relative to the 2012 network 


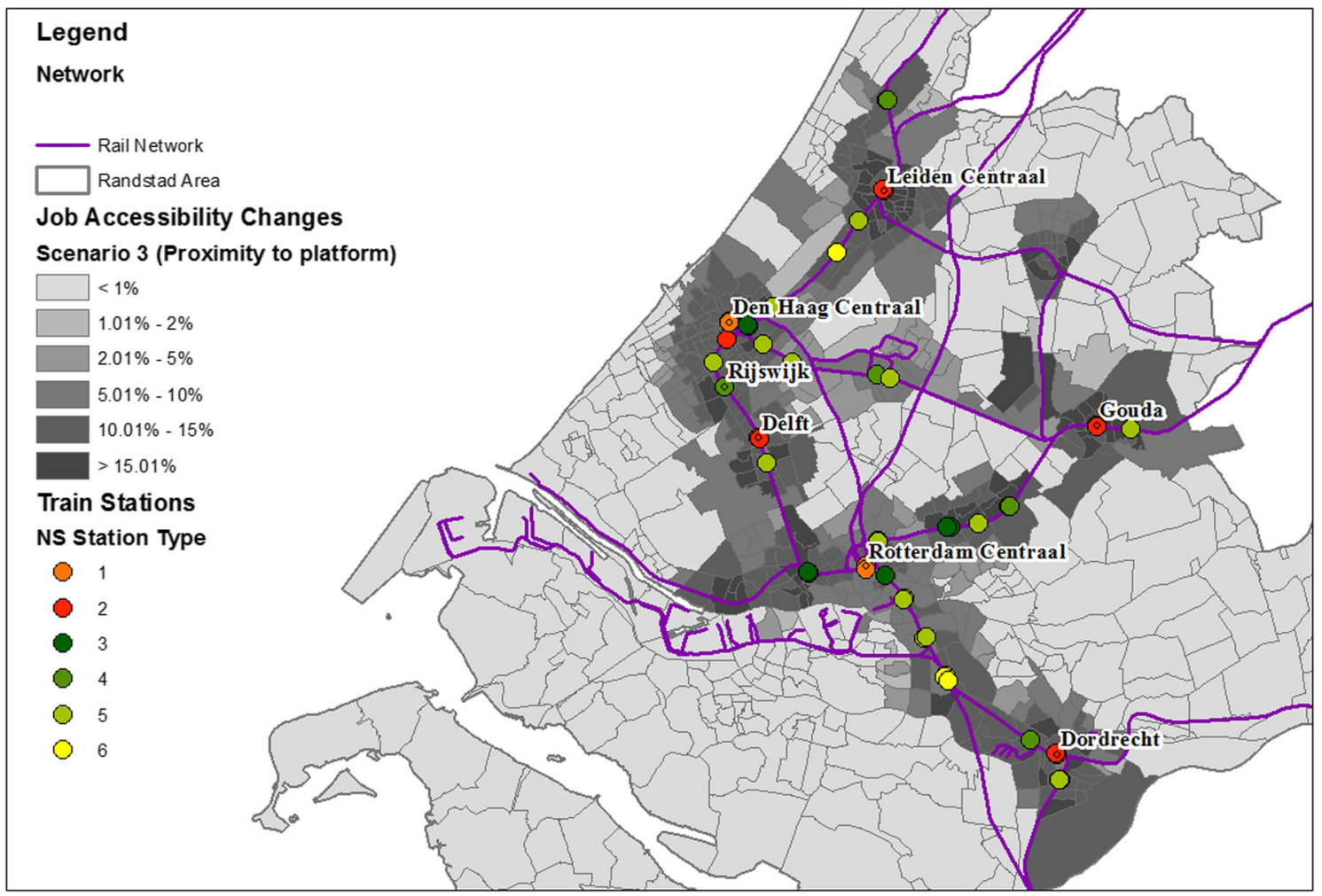

Fig. 5 Effect of bicycle parking within 2 min walking to the platform (scenario 5) on potential job accessibility by public transport in Randstad South, relative to the 2012 network

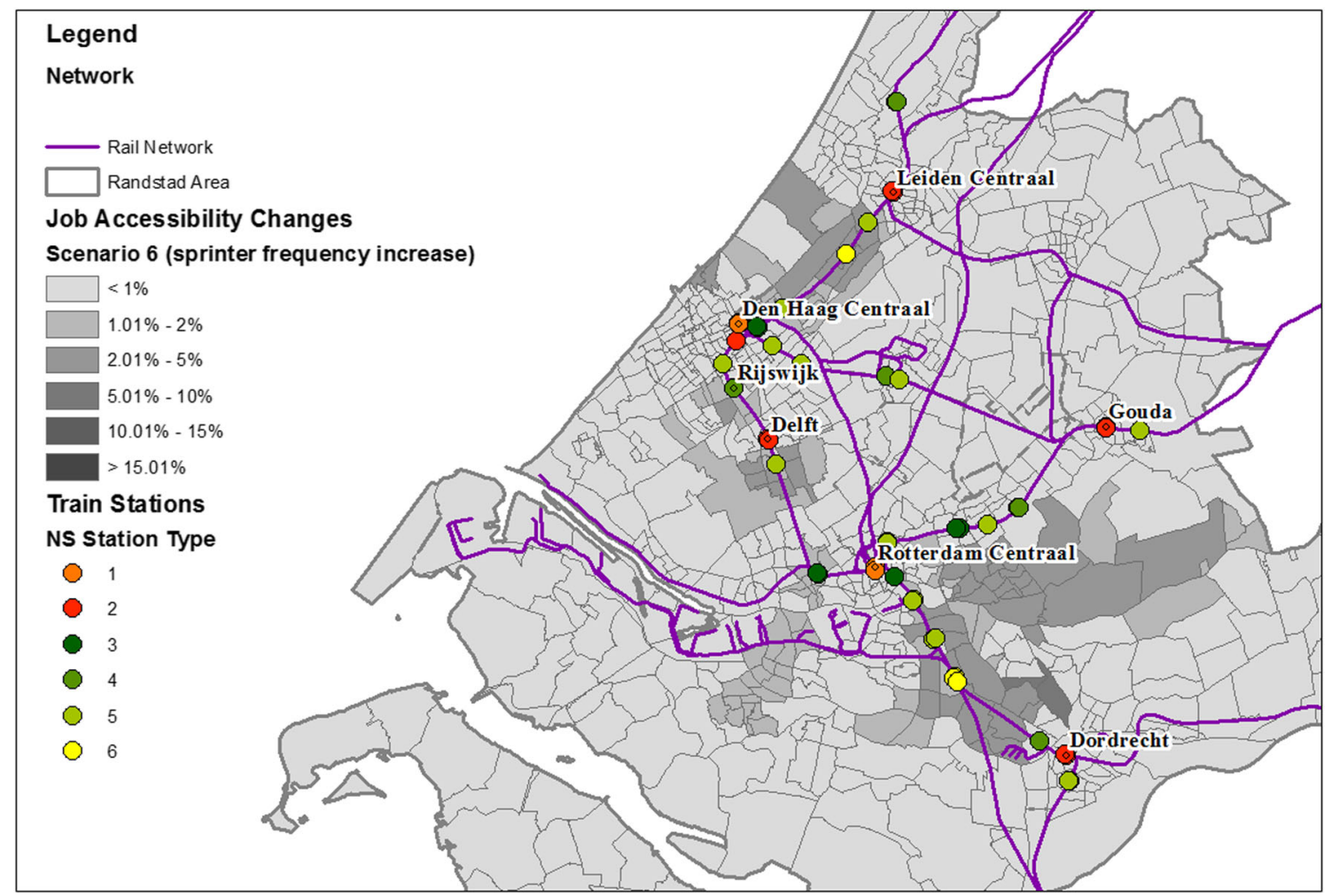

Fig. 6 Effect of increased frequency of local trains in the Leiden-Dordrecht corridor of job accessibility by public transport in Randstad South, relative to the 2012 network 
Potential job accessibility change (percent)

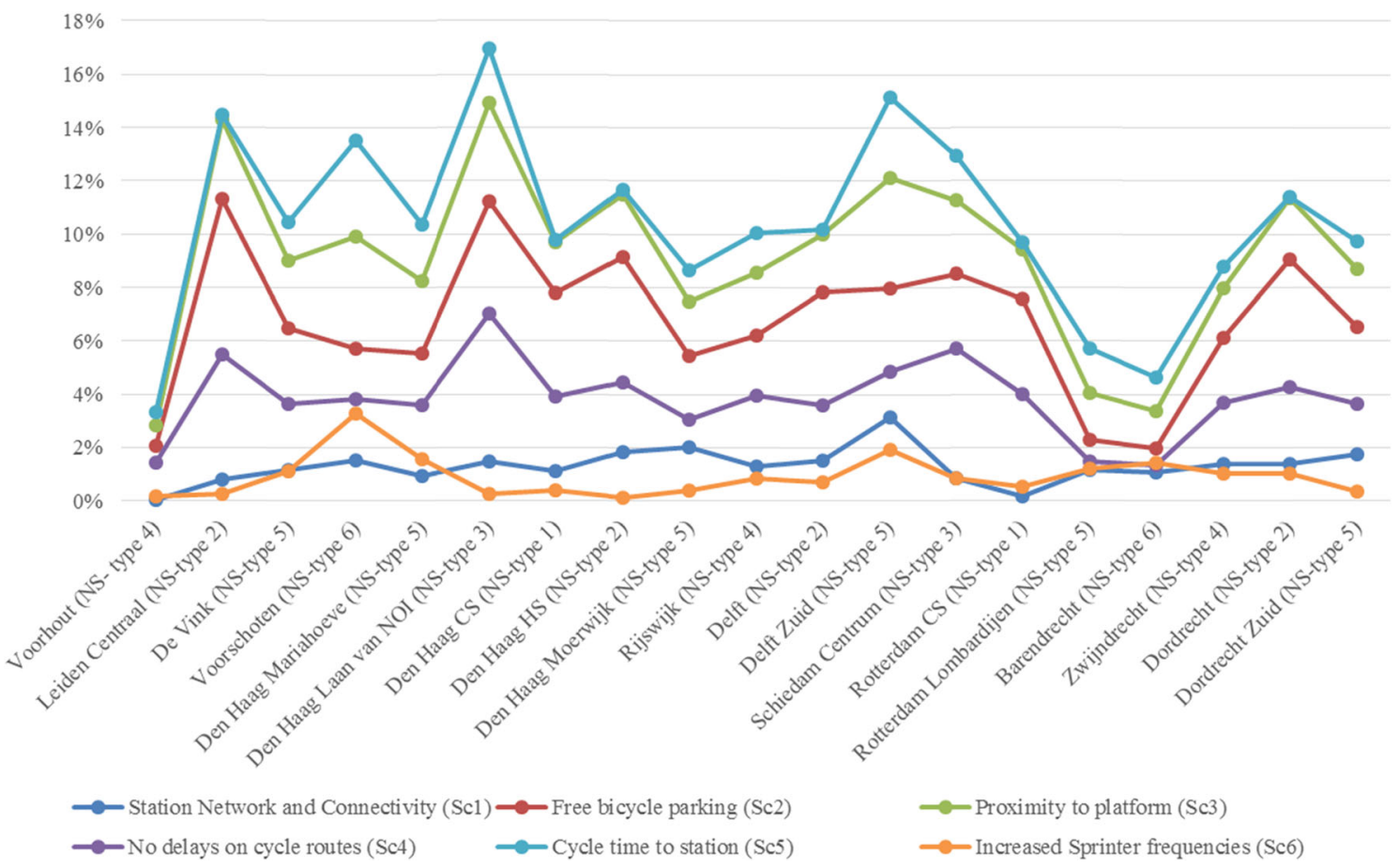

Fig. 7 Effects of policy scenarios on potential job accessibility in the Leiden-Dordrecht corridor, 2012 morning peak

integration policies on train ridership and job accessibility for public transport users. We extended the Dutch National Transport Model (NVM) by implementing a detailed bicycle network linked to the public transport network, access/egress mode combinations and station specific access and egress penalties by mode and station type derived from a stated choice survey. Furthermore, the effects of several bicycle-train integration policy scenarios were examined for a case study for Randstad South, in the Netherlands.

Our analysis shows that improving the quality of bicycle routes and parking can substantially increase train ridership and potential job accessibility for train users. The scenarios illustrate that travel time and cost reductions and to a lesser extent also improvements of the perceived quality of station and bicycle route affect ridership and job accessibility levels. The effects of bicycle-train integration policies substantially vary by station type. Large train stations and commuter trains stations profit more in absolute terms from improvements in bicycle-train integration policies. Most bicycle-train integration policy scenarios examined in this paper are more powerful in producing ridership and job accessibility changes than the scenario with increased local train frequencies in the Leiden-Dordrecht corridor. The different policy measures can however strengthen each other. The bicycle-train integration measures produce relatively strong job accessibility effects around major train stations, whereas the examined train frequency increase has the strongest effect around suburban and smaller train stations. This is a relevant result, as local and regional governments target an increase in the frequency of local trains in the Leiden - Dordrecht corridor by the year 2020. Bicycle-train integration policies are implemented, amongst other measures, to attract train passengers and increase ticket revenues to cover the additional operational cost of the frequency increase.

There are several directions for future research. Firstly, in the NVM-model, the detailed bicycle network belongs to the Randstad area, therefore the effects of bicycle improvements were only measured in this area. It is of special interest to extend this study to a national level. Secondly, the NVM-model estimates travel demand at the aggregate level. The combination of disaggregate discrete mode/ destination choice models with detailed multi-modal networks can produce more robust and behaviourally sound travel demand estimations. Our model partially covered this limitation by applying VoTs and WTPs calculated from a behavioural model. However, the generalised cost function, and mode choice model, the national transport model did not allow further modifications in this respect.

Acknowledgments This work has been funded by the NWO programme Sustainable Accessibility of the Randstad. Also, the authors want to thank Borja Moya for the support on distance decay estimations. The authors also want to thank Goudappel Coffeng for providing the National Transport Model (NVM). 
Appendix

Table 6 Access time reduction for connectivity, station facilities and both

\begin{tabular}{llll}
\hline Station & Connectivity & $\begin{array}{l}\text { Station } \\
\text { facilities }\end{array}$ & $\begin{array}{l}\text { Total access } \\
\text { time } \\
\text { reduction }\end{array}$ \\
\hline Barendrecht & & & $-15 \%$ \\
Capelle Schollevaar & $-5 \%$ & $-10 \%$ & $-13 \%$ \\
De Vink & $-7 \%$ & $-6 \%$ & $-23 \%$ \\
Delft & $-6 \%$ & $-17 \%$ & $-11 \%$ \\
Delft Zuid & $-4 \%$ & $-7 \%$ & $-28 \%$ \\
Den Haag CS & $-8 \%$ & $-20 \%$ & $-4 \%$ \\
Den Haag HS & $-1 \%$ & $-3 \%$ & $-14 \%$ \\
Den Haag Laan van NOI & $-1 \%$ & $-8 \%$ & $-10 \%$ \\
Den Haag Mariahoeve & $-3 \%$ & $-5 \%$ & $-9 \%$ \\
Den Haag Moerwijk & $-7 \%$ & $-16 \%$ & $-24 \%$ \\
Den Haag Ypenburg & $-6 \%$ & $-8 \%$ & $-14 \%$ \\
Dordrecht & $-2 \%$ & $-4 \%$ & $-6 \%$ \\
Dordrecht Zuid & $-7 \%$ & $-18 \%$ & $-26 \%$ \\
Gouda & $-2 \%$ & $-4 \%$ & $-6 \%$ \\
Gouda Goverwelle & $-6 \%$ & $-18 \%$ & $-24 \%$ \\
Leiden Centraal & $-2 \%$ & $0 \%$ & $-2 \%$ \\
Leiden Lammenschans & $-6 \%$ & $-5 \%$ & $-11 \%$ \\
Nieuwerkerk a/d IJssel & $-9 \%$ & $-9 \%$ & $-18 \%$ \\
Rijswijk & $-4 \%$ & $-7 \%$ & $-10 \%$ \\
Rotterdam Alexander & $-2 \%$ & $-5 \%$ & $-7 \%$ \\
Rotterdam Blaak & $-4 \%$ & $-11 \%$ & $-15 \%$ \\
Rotterdam CS & $0 \%$ & $0 \%$ & $0 \%$ \\
Rotterdam Lombardijen & $-5 \%$ & $-10 \%$ & $-15 \%$ \\
Rotterdam Noord & - & $-7 \%$ & $-7 \%$ \\
Rotterdam Zuid & $-10 \%$ & $-13 \%$ & $-22 \%$ \\
Schiedam Centrum & $-3 \%$ & $-7 \%$ & $-11 \%$ \\
Schiedam Nieuwland & $-16 \%$ & $-12 \%$ & $-28 \%$ \\
Vlaardingen Centrum & $-2 \%$ & $-3 \%$ & $-5 \%$ \\
Vlaardingen Oost & $-6 \%$ & $-9 \%$ & $-15 \%$ \\
Voorburg & $-7 \%$ & $-10 \%$ & $-17 \%$ \\
Voorschoten & $-5 \%$ & $-8 \%$ & $-13 \%$ \\
Waddinxveen & $-10 \%$ & $-23 \%$ & $-33 \%$ \\
Zoetermeer & $-9 \%$ & $-10 \%$ & $-19 \%$ \\
Zoetermeer Oost & $-8 \%$ & $-15 \%$ & $-23 \%$ \\
Zwijndrecht & $-4 \%$ & $-11 \%$ & $-16 \%$ \\
\hline & & & \\
\hline
\end{tabular}

Open Access This article is distributed under the terms of the Creative Commons Attribution 4.0 International License (http:// creativecommons.org/licenses/by/4.0/), which permits unrestricted use, distribution, and reproduction in any medium, provided you give appropriate credit to the original author(s) and the source, provide a link to the Creative Commons license, and indicate if changes were made.

\section{References}

1. Martens K (2007) Promoting bike-and-ride: the Dutch experience. Transp Res A Policy Pract 41(4):326-338

2. Pucher J, Buehler R (2009) Integrating bicycling and public transport in North America. Journal of Public Transportation 12(3):79-104

3. Brons M, Givoni M, Rietveld P (2009) Access to railway stations and its potential in increasing rail use. Transp Res A Policy Pract 43(2):136-149

4. La Paix Puello L, Geurs KT (2016) Integration of unobserved effects in generalised transport access costs of cycling to railway stations. European Journal of Transport Infrastructure Research 16(2):385-405

5. Givoni M, Rietveld P (2007) The access journey to the railway station and its role in passengers' satisfaction with rail travel. Transp Policy 14(5):357-365

6. Lei T, Chen Y, Goulias K (2012) Opportunity-based dynamic transit accessibility in Southern California. Transportation Research Record.

7. Lei TL, Church RL (2010) Mapping transit-based access: integrating GIS, routes and schedules. Int J Geogr Inf Sci 24(2):283-304

8. Mavoa S, Witten K, McCreanor T, O'Sullivan D (2012) GIS based destination accessibility via public transit and walking in Auckland, new Zealand. J Transp Geogr 20(1):15-22

9. Iacono M, Krizek KJ, El-Geneidy A (2010) Measuring nonmotorized accessibility: issues, alternatives, and execution. J Transp Geogr 18(1):133-140

10. Lin T, Xia J, Robinson TP, Goulias KG, Church RL, Olaru D, Tapin J, Han R (2014) Spatial analysis of access to and accessibility surrounding train stations: a case study of accessibility for the elderly in Perth, Western Australia. J Transp Geogr 39(0):111-120

11. Moniruzzaman M, Páez A (2012) Accessibility to transit, by transit, and mode share: application of a logistic model with spatial filters. $J$ Transp Geogr 24:198-205

12. van Eck G, Brands T, Wismans L, Pel A, van Nes R (2014) Model Complexities and Requirements for Multimodal Transport Network Design. Assessment of Classical, State-of-the-Practice, and Stateof-the-Research Models. Transportation Research Record. Journal of the Transportation Research Board (2429):178-187

13. Liao F, Arentze T, Timmermans H (2010) Supernetwork approach for multimodal and Multiactivity travel planning. Transportation Research Record: Journal of the Transportation Research Board 2175:38-46

14. van Wee B, Bohte W, Molin E, Arentze T, Liao F (2014) Policies for synchronization in the transport-land-use system. Transp Policy 31(0):1-9

15. Vande Walle S, Steenberghen T (2006) Space and time related determinants of public transport use in trip chains. Transp Res A Policy Pract 40(2):151-162

16. Schakenbos R, Paix LL, Nijenstein S, Geurs KT (2016) Valuation of a transfer in a multimodal public transport trip. Transp Policy 46:72-81

17. La Paix Puello L, KT Geurs (2016) Train station access and train use: A joint stated and revealed preference choice modelling study. In: Geurs KT, Patuelli R, Dentinho T (eds) Accessibility, Equity and Efficiency. Challenges for transport and public services. Edward Elgar (forthcoming), Northampton, USA.

18. Van Hagen M (2011) Waiting experience at train stations. Phd Thesis. University of Twente, the Netherlands

19. Cascetta E, Cartenì A (2014) The hedonic value of railways terminals. A quantitative analysis of the impact of stations quality on travellers behaviour. Transp Res A Policy Pract 61(0):41-52

20. Cartenì A, Galante G, Henke I (2014) The catchment area of high architectural railway stations: an application of the Graham scan algorithm. WIT transactions on the built. Environment:463-474 
21. Chang JS, Lee J-H (2008) Accessibility analysis of Korean highspeed rail: a case study of the Seoul metropolitan area. Transport Reviews: A Transnational Transdisciplinary Journal 28(1):87-103

22. Goudappel Coffeng (2011) Nationaal Model 2.0 2008-2020. Technische rapportage. Goudappel Coffeng, Deventer

23. de Dios Ortúzar J, Willumsen LG (2011) Modelling transport, 4th edn. Wiley, Chichester, UK

24. Significance (2013) Values of time and reliability in passenger and freight transport in The Netherlands.

25. Brands T, De Romph E, Veitch T, Cook J (2014) Modelling Public Transport Route Choice, with Multiple Access and Egress Modes. Transportation Research Procedia 1(2014):12-23

26. Fietsersbond (2013), Database Bicycle Route Planner South Holland. Fietsersbond, Utrecht.

27. Bhat C, Handy S, Kockelman K, Mahmassani H, Chen Q, Weston L (2000) Accessibility measures: formulation cosiderations and current applications. Unviersity of Texas at Austin.

28. Handy SL, Niemeier DA (1997) Measuring accessibility: an exploration of issues and alternatives. Environment and Planning A 29: 1175-1194

29. Geurs KT, van Wee B (2004) Accessibility evaluation of land-use and transport strategies: review and research directions. J Transp Geogr 12(2): 127-140

30. Wachs M, Kumagai TG (1973) Physical accessibility as a social indicator. Socio-economic planning. Science 6:357-379

31. Hansen WG (1959) How accessibility shapes land use. Journal of American Institute of Planners 25(1):73-76

32. de Jong G, Daly A, Pieters M, van der Hoorn T (2007) The logsum as an evaluation measure: review of the literature and new results. Transp Res A Policy Pract 41(9):874-889

33. Geurs K, Zondag B, De Jong G, Md B (2010) Accessibility appraisal of integrated land-use/transport policy strategies: more than just adding up travel time savings. Transportation Research Part D 15:382-393

34. Cascetta E, Cartenì A, Montanino M (2016) A behavioral model of accessibility based on the number of available opportunities. J Transp Geogr 51:45-58

35. Kwan M-P (1998) Space-time and integral measures of individual accessibility: a comparative analysis using a point-based framework. Geogr Anal 30(3):191-216

36. Thill JC, Kim M (2005) Trip making, induced travel demand, and accessibility. J Geogr Syst 7(2):229-248
37. Ahlfeldt $\mathrm{G}$ (2011) If alonso was right: modeling accessibility and explaining the residential land gradient. J Reg Sci 51(2):318-338

38. Helling A (1998) Changing intra-metropolitan accessibility in the U.S.: evidence from Atlanta. Prog Plan 49 (2):iii-107

39. Östh J, Lyhagen J, Reggiani A (2016) A new way of determining distance decay parameters in spatial interaction models with application to job accessibility analysis in Sweden. EJTIR 16(2):319 343

40. Reggiani A, Bucci P, Russo G (2011) Accessibility and impedance forms: empirical applications to the German commuting network. Int Reg Sci Rev 34(2):230-252

41. de Vries JJ, Nijkamp P, Rietveld P (2009) Exponential or power distance-decay for commuting? An alternative specification. Environment and Planning A 41(2):461-480

42. CBS (2015) Onderzoek Verplaatsingen in Nederland 2014. Onderzoeksbeschrijving [National Travel Survey 2014. Research description]. Statistics Netherlands, The Hague

43. Geurs KT, Ritsema van Eck JR (2003) Accessibility evaluation of land-use scenarios: the impact of job competition, land-use and infrastructure developments for the Netherlands. Environment and Planning B: Planning \& design 30(1):69-87

44. Thorsen I, Ubøe J, Nævdal G (1999) A network approach to commuting. J Reg Sci 39(1):73-101

45. Progammabureau Stedenbaan (2012) Stedenbaanmonitor 2012. Platform Zuidvleugel, Den Haag

46. La Paix Puello L, Geurs K (2015) Modelling observed and unobserved factors in cycling to railway stations: application to transitoriented-developments in the Netherlands. European Journal of Transport Infrastructure Research 15(1):27-50

47. Wardman M (2001) A review of British evidence on time and service quality valuations. Transportation Research Part E: Logistics and Transportation Review 37(2-3):107-128

48. Wardman M (2004) Public transport values of time. Transp Policy 11(4):363-377

49. Debrezion G, Pels E, Rietveld P (2009) Modelling the joint access mode and railway station choice. Transportation Research Part E: Logistics and Transportation Review 45(1):270-283

50. Balz V, Schrijnen J (2011) From Concepts to Projects: Stedenbaan, the Netherlands. In: Curtis C, Renne JL, Bertolini L (eds) Transit Oriented Development. Making it happen. Ashgate, Farnham/ Burlington

51. Molin E, Maat K (2015) Bicycle parking demand at railway stations: capturing price-walking trade offs. Res Transp Econ 53:3-12 